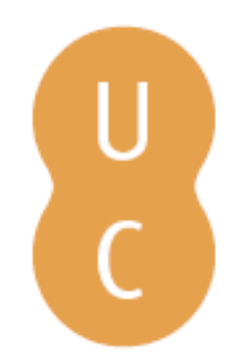

\title{
pompalina
}

\section{Cataldo e a defesa da Europa}
Autor(es):
Ramalho, A. Costa
Publicado por: Imprensa da Universidade de Coimbra
URL persistente:
URI:http://hdl.handle.net/10316.2/38950
DOI:
DOl:http://dx.doi.org/10.14195/978-989-26-0395-7_4

Accessed : $\quad$ 26-Apr-2023 09:00:22

A navegação consulta e descarregamento dos títulos inseridos nas Bibliotecas Digitais UC Digitalis, UC Pombalina e UC Impactum, pressupõem a aceitação plena e sem reservas dos Termos e Condições de Uso destas Bibliotecas Digitais, disponíveis em https://digitalis.uc.pt/pt-pt/termos.

Conforme exposto nos referidos Termos e Condições de Uso, o descarregamento de títulos de acesso restrito requer uma licença válida de autorização devendo o utilizador aceder ao(s) documento(s) a partir de um endereço de IP da instituição detentora da supramencionada licença.

Ao utilizador é apenas permitido o descarregamento para uso pessoal, pelo que o emprego do(s) título(s) descarregado(s) para outro fim, designadamente comercial, carece de autorização do respetivo autor ou editor da obra.

Na medida em que todas as obras da UC Digitalis se encontram protegidas pelo Código do Direito de Autor e Direitos Conexos e demais legislação aplicável, toda a cópia, parcial ou total, deste documento, nos casos em que é legalmente admitida, deverá conter ou fazer-se acompanhar por este aviso.

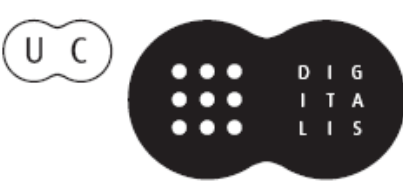


Nair de Nazaré Castro Soares

Santiago López Moreda

Coordenação

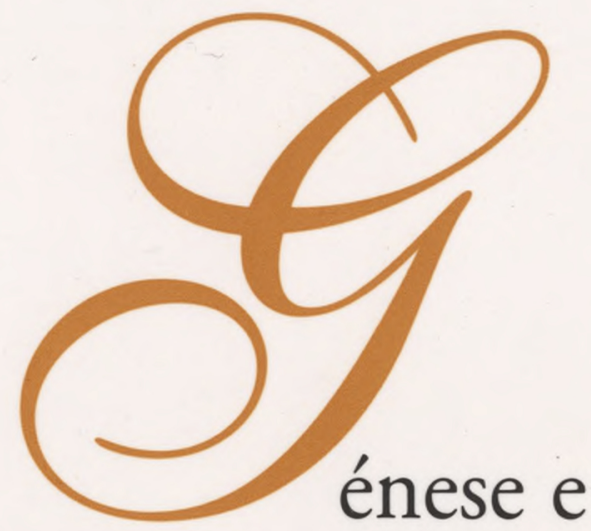

Consolidação da Ideia de Europa

Vol. IV

Idade Média e Renascimento

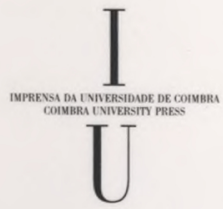

- COIMBra 2009 


\title{
CATALDO E A DEFESA DA EUROPA
}

\author{
A. Costa Ramalho \\ (Universidade de Coimbra)
}

Quando o humanista Cataldo Parísio Sículo chegou a Portugal em 1485, trazia consigo um poema para oferecer ao rei D. João II, quer em homenagem a quem o convidara, quer como documento dos seus méritos de poeta latino.

Cataldo fora contratado por D. João II para desempenhar as funções de secretário latino do soberano português, com o título oficial de orator mas sobretudo para mestre e educador de D. Jorge, o filho de D. João II e de D. Ana de Mendonça.

Não que em Portugal não houvesse mestres competentes, algum dos quais antigo estudante de Itália poderia ser escolhido para ensinar o pequeno príncipe nascido em 1481. O soberano, todavia, deve ter querido eximir o seu filho bastardo a influências interesseiras e ao mundo de intrigas da corte, escolhendo para seu professor um humanista estrangeiro.

$\mathrm{O}$ intermediário na contratação de Cataldo Parísio foi o clérigo Fernando Coutinho, mais tarde bispo de Lamego e de Silves, que então estudava em Itália. Coutinho deve ter conhecido Cataldo por intermédio de Antonio Corsetti, professor da Universidade de Bolonha e siciliano como o próprio Cataldo.

Corsetti e Cataldo tinham sido outrora rivais na candidatura a um posto de reitor-estudante nessa mesma universidade. Corsetti vencera e seguira a carreira académica na universidade bolonhesa, em cuja Faculdade de Direito pontificava um outro siciliano, o famoso Andrea Barbazza a quem Corsetti veio a suceder ${ }^{1}$.

Voltemos porém ao presente que Cataldo preparara para oferecer ao rei de Portugal. Tratava-se do poema Arcitinge, em hexâmetros dactílicos latinos.

\footnotetext{
' Ver A. Costa Ramalho, Estudos sobre a Época do Renascimento, Lisboa, FCG/JNICT, 1997, p.48.
} 
O título Arcitinge é uma palavra composta, criada por Cataldo, para juntar o nome de duas cidades do Norte de África, Arcilla e Tingis, isto é, Arzila e Tânger.

$\mathrm{O}$ tema é a conquista das duas cidades em 1471 por D. Afonso $\mathrm{V}$ e seu filho D. João que na altura tinha apenas dezasseis anos de idade. É sabido que só a custo $\mathrm{D}$. Afonso $\mathrm{V}$ consentiu na presença do príncipe herdeiro, por considerar a aventura africana demasiado arriscada.

Cataldo, ao escrever o poema, pretendia homenagear os dois soberanos, pai e filho, apesar de D. Afonso V ser já falecido em 1485.

A Arcitinge não é um seco poema latino em versos mais ou menos frios. Tem vida e colorido.

Não pretendo dar dele aqui um resumo, por já o ter feito em outras ocasiões. Direi apenas que o poeta participa vivamente das emoções dos combatentes lusitanos. O poema pode ser lido em tradução portuguesa no meu livro Latim Renascentista em Portugal (1 $1^{a}$ edição, 1985; $2^{a}$ edição, 1993).

Para Cataldo, as guerras de Itália, motivadas por ambições pessoais, fora de toda a grandeza política ou religiosa, são apenas questiúnculas menores. As verdadeiras lutas de interesse para a Cristandade travam-se em África e nelas o rei de Portugal D. João II está mais empenhado que qualquer outro soberano da Europa.

Cataldo fora certamente informado sobre as coisas portuguesas por Fernando Coutinho e, como atrás disse, deve ter trazido o poema quase redigido por completo e apenas aperfeiçoou pormenores depois de residir em Portugal.

A simpatia pelo assunto, a guerra contra os Mouros de África, é evidente no humanista recém-chegado. Do que ele pensava da barbárie africana e do Mouro inimigo do Europeu, pode ler-se nos versos 86 e seguintes:

\section{Effera nimirum gens est ac nescia cuiquam}

Parere imperio, nullis conterrita factis (...)

É uma gente verdadeiramente selvagem que não sabe submeter-se a poder algum, e a quem nada aterroriza $(\ldots)$

O resto da diatribe pode ler-se no texto latino e respectiva tradução, de verso 87 em diante, no meu livro Latim Renascentista em Portugal.

Cataldo pediu repetidas vezes aos soberanos e a nobres do seu conhecimento informações sobre os acontecimentos de África e da Índia, ao que parece, sem grande resultado, ou melhor, o humanista queixa-se de que nunca recebeu ao menos um relatório do que se passava na África e na Ásia. Um 
desses relatórios é pedido numa carta que envia a Aires Teles ${ }^{2}$ para que seguramente a faça chegar às mãos do rei D. Manuel.

Quanto ao Norte de África era mais fácil colher informações pois as grandes famílias com quem estava em contacto e cujos filhos ensinava, tinham quase todas membros seus a combater em solo africano: a casa de Bragança onde ensinava D. Dinis, irmão mais novo do duque D. Jaime; a casa de Vila Real onde era professor de D. Pedro de Meneses, conde de Alcoutim, e de sua irmã D. Leonor de Noronha; a Casa de Tarouca a que pertencia D. Henrique de Meneses, filho do conde D. João; e outros como Martim de Sousa, comandante em África, a quem escreveu uma carta memorável.

Com efeito, essa epístola desmente a visão tradicional das épocas de D. João II e D. Manuel como tempos medievos, de rudes barões guerreiros e incultos. Cataldo pede a este seu amigo informações a respeito da campanha militar em que está envolvido, para a não esquecer nas crónicas que vem escrevendo sobre a actividade militar dos portugueses nos diversos pontos do mundo. E aproveita a oportunidade para felicitar Martim de Sousa por ter mandado vir de Sevilha um professor, a fim de ensinar latim aos rapazes no intervalo dos combates. Esse professor podia muito bem ter sido Estêvão Cavaleiro ${ }^{3}$, então homiziado de Portugal.

No discurso de saudação à princesa Isabel, filha dos Reis Católicos, na sua entrada solene em Évora, como mulher do príncipe herdeiro D. Afonso, no domingo 28 de Novembro de 1490, Cataldo, elogiando o rei de Portugal, afirma que sob o mando de D. João II os portugueses já conhecem o caminho marítimo para a Índia. Mas esta é uma informação de certo encomendada pelo rei de Portugal "para Castelhano ouvir", isto é, dirigida aos membros da comitiva espanhola da princesa.

E afinal, talvez por falta das informações pedidas, Cataldo só fala de um navegador português, Miguel Corte-Real. E esse mesmo aparece nos versos do humanista, não como navegador mas como guerreiro de África. Com efeito, na esquadra que em 1501 sob o comando do conde de Tarouca, D. João de Meneses, socorreu os Venezianos contra os Turcos, ia uma flotilha encarregada da missão secreta de no caminho atacar de surpresa o forte que defendia Orão e apoderar-se da cidade. $\mathrm{O}$ ataque foi mal sucedido, e só não se tornou um desastre, porque Miguel Corte-Real com alguns companheiros cobriu a retirada

${ }^{2}$ Cf. Cataldo Parisio Sículo, Epistolas, II parte. Fixação do texto latino, tradução, prefácio e notas de Américo da Costa Ramalho e de Augusta Fernanda Oliveira e Silva, Lisboa, INCM, 2005, p.115.

${ }^{3}$ Ver A. Costa Ramalho, Para a História do Humanismo em Portugal, I, Lisboa, INIC, 1988, p.7-13. 
dos atacantes. Cataldo celebra o feito, que é desconhecido dos historiadores, num poema em que considera Miguel Corte-Real digno dos versos de Homero.

Nesse poema, que tive a honra de revelar há $\operatorname{anos}^{4}$, Cataldo elogia as qualidades pessoais de Miguel Corte-Real que no seu alto cargo de porteiromor do palácio da Alcáçova desempenha as complexas funções que lhe incumbem com segura competência, apesar de não ter feito em devido tempo estudos literários.

Talvez em resposta a esta reserva final de Cataldo, há uma carta no

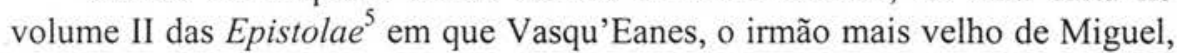
é elogiado pelo seu excelente latim que Cataldo admirou numa carta dele recebida.

Voltando porém ao tema principal do presente artigo, é o momento de perguntar por que razão o humanista siciliano dá preferência à matéria africana sobre a das descobertas marítimas.

Uma primeira resposta será a de que no caso das descobertas lhe foram negadas as informações que ele pedia. Outra, e a meu ver a principal razão certamente a de que Cataldo vivia o problema da presença africana nas costas da sua Sicília natal.

Há uma carta do humanista para D. João Manuel, camareiro-mor do rei D. Manuel, em que Cataldo insta com o fidalgo português para que consiga que o seu rei fale ao sogro urgentemente num assunto que o soberano português prometera resolver com Fernando, o Católico.

Num artigo (cf. nota 7$)^{6}$ dedicado a este caso, cheguei à conclusão de que se tratava de conseguir que Fernando, o Católico, ordenasse ao Vice-rei da Sicília, seu subordinado, que tomasse medidas drásticas para impedir os ataques constantes de piratas africanos aos campos e à própria cidade de Sciacca na costa sudoeste da Sicília.

Por informações de outras de Cataldo chega-se à conclusão de que Sciacca era provavelmente a sua terra natal. Isto é, ao referir-se em diversas cartas aos ataques dos Mouros às costas sicilianas, Cataldo sabia do que estava a tratar. Há mesmo uma epístola de D. João II pela qual somos informados de que o rei de Portugal interviera na libertação de um patrício de Cataldo, junto do rei de Tunis $(E p \mathrm{I}, \mathrm{h})^{7}$.

Este grave problema da actividade naval e bélica de Turcos e Mouros no mar Mediterrâneo interessava a toda a Europa e em especial à Península Ibé-

\footnotetext{
${ }^{4}$ Ver A. Costa Ramalho, Estudos sobre o século XVI, Lisboa, INCM, ${ }^{2} 1983$, p. 77-94.

${ }^{5}$ Vide o livro citado na nota 2, pág. 37

${ }^{6}$ Cf. Cataldo Ep I e 3 - e 3 v.. .

${ }^{7}$ Cf. A. Costa Ramalho, «Uma carta de Cataldo ao camareiro-mor D. João Manuel», A Antiguidade Clássica e Nós Herança e Identidade cultural, Braga, Universidade do
} Minho, 2006, p.287-292. 
rica, pois temia-se uma nova invasão islâmica nas duas extremidades do continente europeu, como as de sete séculos antes. Por isso, na conquista de Granada combateram portugueses como D. Francisco de Almeida, futuro vice-rei da Índia, e D. Álvaro de Bragança, personagem de relevo na poderosa casa ducal.

D. Francisco de Almeida não se encontra na prosa ou nos versos de Cataldo, mas seu irmão, D. Diogo, cavaleiro de Rodes e futuro prior do Crato, que foi também aio de D. Jorge, o educando de Cataldo, ai figura com proeminência. Com efeito, o seu heróico curriculum uitae, iniciado na guerra de África aos dezasseis anos de idade, foi composto em latim por Cataldo e incluído no seu epistolário (Ep. $I, \mathrm{c} 4 \mathrm{v}^{\circ}$. - c $5 \mathrm{v}^{\circ}$.).

D. Diogo de Almeida travou ainda numerosos combates navais no Mediterrâneo Oriental, em defesa de Rodes, enquanto outros navios portugueses ajudavam à conquista de Granada, impedindo a passagem de socorros, por via marítima, aos mouros cercados.

Assim, prosa e verso de Cataldo reflectem os graves problemas da defesa da Europa, no último quartel do século XV e nas duas décadas iniciais do século seguinte.

Em 1991, Luís de Matos publicou o seu importante livro, L'Expansion Portugaise dans la Litterature Latine de la Renaissance (Lisboa, Fundação C. Gulbenkian). A obra apresenta-se como edição da sua tese de "Doctorat d'Etat" na Sorbonne em 1959. Isto permite ao autor não citar bibliografia publicada entre 1959 e 1991. Justificando este procedimento, o prefaciador J.V. Pina Martins escreveu: "É verdade que, acerca de Cataldo Sículo, Américo da Costa Ramalho editou algumas contribuições valiosas, mas que se situam, de maneira geral, numa área da filologia humanística e não historiográfica" (página XXVII).

Isto não é exacto. Nos meus livros, Estudos sobre a Época do Renascimento (1969; $2^{\mathrm{a} e d i c ̧ a ̃ o, ~ 1997) ; ~ E s t u d o s ~ C a m o n i a n o s ~(1975 ; ~} 2^{\mathrm{a}}$ edição 1980); Estudos sobre o século XVI (1980; $2^{\mathrm{a}}$ edição aumentada, 1983); Latim Renascentista em Portugal (1985; $2^{\mathrm{a}}$ edição, 1993); Para a História do Humanismo em Portugal, vol. I (1988), todos publicados em $1^{a}$ edição antes de 1991, há referências à expansão ultramarina dos portugueses não apenas em Cataldo mas também noutros humanistas.

E o mesmo acontece em artigos dispersos como "No nono centenário da Universidade de Bolonha: Cataldo e Bolonha" (1988); "Cataldo e D. João II" 
(1988); "O conimbricense Mem de Sá, terceiro governador-geral do Brasil" (1989) e em alguns mais encontram-se igualmente referências a África, Ásia e Brasil.

Um artigo merece nota especial. Intitula-se "Cataldo e a expansão portuguesa" e foi publicado no meu livro Para a História do Humanismo em Portugal, vol. III, (1998), mas no Prólogo explico: "foi entregue, há anos, aos editores de uma Miscelânea que não foi publicada". Afinal a Miscelânea foi publicada nesse mesmo ano em Paris, e é o volume XXXVII dos Arquivos do Centro Cultural Calouste Gulbenkian, em honra da Prof. Doutora Maria de Lourdes Belchior. Aí se encontram numerosas referências a Cataldo e ao Ultramar publicadas antes de 1991. Na verdade, o artigo fora enviado para outra Miscelânea em honra de Maria de Lourdes Belchior, antes do seu falecimento, a qual não tendo saído na altura própria, o material então reunido passou para a Miscelânea de 1998. Mas o artigo em questão fora escrito anos antes. 